\title{
Evaluation of Physiochemical characteristics of disposed Rubber industry effluent: A Case study of Bodhjungnagar Industrial Growth Centre
}

\author{
Amarendra Jamatia ${ }^{1}$, Sukanta Chakraborty ${ }^{2}$, Debabrata Das ${ }^{3}$, Sabbir Kumar \\ Jamatia $^{4}$, Dr. Srimanta Ray ${ }^{5}$, Dr. Mihir Kr. Das ${ }^{6}$ \\ 1(Asst. Environmental Engineer, Tripura State Pollution Control Board, Tripura, India)E-mail: amarendrajamatial4@gmail .com \\ 2( M. Tech Scholar, Department of Civil Engineering, NIT Agartala,Tripura, India),E-mail:sukanta.chakra@gmail.com \\ 3 ( M. Tech Scholar, Department of Civil Engineering, NIT Agartala, Tripura, India)LE-mail: debabrata7910@ gmail.com \\ 4 ( Asst. Professor, Tripura Institute of Technology, Tripura, India)E-mail: sabbirkumarjamatia@gmail.com \\ 5( Asst. Professor, National Institute of Technology, Agartala, Tripura, India)E-mail: srimanta.chemical@nita.ac.in \\ 6 (Scientist-C, Tripura State Pollution Control Board,Tripura, India),E-mail: mihir_das1965@ rediffmail.com
}

\begin{abstract}
The suitable agro-climate conditions are making the Tripura State into second largest rubber producer in country, India. Rapid growth of rubber production and rubber based industries has resulted rapid economy growth of the State. Despite the derived economy benefit, the rubber based industry generates large quantities of effluents during the various stages of processing. The production process of commercial rubber products causes serious water pollution problems. Massive disposal of effluents in to inland water surface often causes damage to the precious water resources. Surface water resources are the greatest victims due to effluent of rubber processing industries. The present study is aimed to quantify the trend of deterioration of water quality within the study area and its resulting impacts on the surface water resources due to inland disposal of effluent from the rubber based industries of Bodhjungnagar Industrial Growth Centre. Major causes of deterioration of water quality are due to high BOD load, high concentration of suspended solid and nitrogen content. Different extents of acid usage in various sections of rubber processing industries are also responsible for $\mathbf{p H}$ variation and causing acidic effluent. Such a study is an attempt to redress the water pollution problem in the Bodhjungnagar Industrial Growth Centre.
\end{abstract}

Keywords: - Rubber industry effluent, Physiochemical characteristics, rubber processing, water pollution.

\section{INTRODUCTION}

Tripura is the second largest rubber producer in the country, India. The suitable agro-climate conditions such as favorable climate, tropical monsoon, fertile soils etc. are responsible to make the State into second largest rubber producer in the Country. Here, approximately 37558 hectors of area are being used for cultivation of rubber plantation in the State. Out of which, 29581 hectors land area are declared as trapping area and rest 7977 hectors land as newly cultivated area. Total potential for rubber plantation in the State is 100000 hectors. The average annual production of rubber is 20000 MT during 2013-14. It is estimated that the rubber production is likely to be crossed more than 25000 MT within next 5-6 years as the trapping area is increasing day by day. The rapid growth of commercial rubber production and rubber based industries of course playing an important role in economic development of the State. However, associated environmental problems for treatment and disposal of effluent especially rubber based industries cannot be ignored [1]. Because, the commercial production process of rubber products from latex needs large amount of water. Apart from the water, some chemicals are used as additives used to manufacture rubber and produces enormous amounts of effluent in the waste streams. Discharge of untreated effluent to any water bodies, has resulted in water pollution. Hence, arresting the pace of degradation of environment due to imperative of high economic growth is the major challenge now-a-days.

Many investigators studied the pollution associated with different small and large scale industries including the agricultural product processing industries. Within the studies water pollution was focused, some have examined emissions [2]. The studies on water pollution have concentrated on various industries in different 
countries: the sugar industry [3] and distilleries in India [4], food processing, textiles, paper, oil refining and chemical industries in China [5], and organic water pollution from the industries in Indonesia [6]. A study is also made regarding the environmental condition of the whole Bodhjungnagar Industrial Complex of Tripura [7]. In this article the physiochemical characteristics of the effluent generated by the Rubber processing industries of the Bodhjungnagar Industrial Complex of Tripura and its probable impact have been studied.

\section{DESCRIPTION OF STUDY AREA}

The Government of Tripura has set up one Rubber Park in Bodhjung Nagar Industrial Growth Centre area with the technical support of Rubber Board, Government of India. There are 50 acres of land allotted for Rubber Park, 126.12 acres of land allotted for Export Promotion Industrial Park, 30 acres for Food Processing Technology Parks, and 238.53 acres of land for Industrial Growth centre. It is the largest industrial estate of the Tripura State, India. Bodhjung Nagar Industrial Growth Centre has started its journey during the year 1998. As per the Survey of India Toposheets, the proposed study area falls in Toposheet No. 79 M/5 with Latitudinal Extent of N $23^{0} 51^{\prime} 30^{\prime \prime}$ and Longitudinal Extent E $91^{\circ} 20^{\prime}$ to E $91^{\circ} 25^{\prime}$. Howrah River is only Perennial River near the site, which is situated at distance of $6 \mathrm{k} . \mathrm{m}$. from the site towards South. Adjacent micro watersheds of the site comprise of numerous second \& third orders seasonal streams/rivulets; some of them joined to the Howrah River. However, one of the important rivulets namely Lalmatti Chhara which later joined Katakhal drains. The rivulet remains dry during the most parts of the year. After traversing 8-12 Km., Katakhal later passes through Agartala Municipal Corporation. One of the tributes namely Devta Chhara of Howrah River is passing little away from the site which is also a seasonal stream. Devta Chhara latter joined with the river Howrah after Khayerpur. There are many rural settlements adjacent to Bodhjungnagar Growth Centre such as residential quarter complex of NEEPCO, Nipendranagar, R.K Nagar and other hamlets of Bodhjungnagar. The Headquarter of Tripura State Rifles, $2^{\text {nd }}$ Battalion is located near the Bodhjung Nagar Industrial Growth Centre.

\section{NATURAL RUBBER PROCESSING}

Basically, there are two types of rubber processing industries in Bodhjungnagar Industrial Growth Centre. One is rubber sheet processing and another one is processing of crepe rubber. Both types of industries are based on natural latex. Natural latex is mainly tapped from the harvested rubber plantation. The latex is a sticky, milky colloidal suspension. The process of making incisions into the bark and collecting the milky fluid in vessels is called "tapping". The latex from the collection cups are collected by pouring the contents of the collection cups into a larger container before replacing the collection cup into its original position. The tapped latex is being processed to make it commercial products. The process to produce commercial rubber involves many engineering applications \& various stages of processed works. The production process of rubber products from latex needs large amount of water and some chemicals such diluted ammonia, hydrogen phosphate etc. as additives. Depending upon the final products \& quality of rubber, the processing is categories in to the followings

\section{Processing of rubber sheet:}

Rubber sheets are manufactures using the rolling machine. Appropriate quantities of formic acid are added as additive and mixed with the field latex for rubber sheet manufacturing. Formic acid added field latex is kept for $24 \mathrm{hrs}$ before rolling. The additive mixed wet sheet is embossed into rolling machine to achieve desired thickness of sheet and also to remove water contents. The sheets are being dried either by air or in a smoke house for a period of 7 days at a standard temperature. Open drying causes foul odour in and around, hence open drying is prohibited in Tripura State. Instead of open drying, smoke house is most desirable for drying of rubber sheets. In Tripura, woods fired smokehouse is commonly practiced for drying of rubber sheets.

\section{Processing of Crepe rubber:}

Crepe rubber is made from field latex. Field latex contained with $25-32 \%$ dry rubber content (DRC). In order to increase the DRC of field latex, centrifuging is being done by injecting the ammonia (either gaseous form) in the centrifuge unit. Centrifuged latex as preserved by adding ammonia is transfer to the coagulation tank. Acetic acid solution of $10 \%$ is normally used to neutralize the ammonia in coagulation tank. Water of adequate quantities is also added to the coagulation tank for floating up the coagulum. The slab of coagulum is then passed through the roller which reduces the water content and increase the surface area for drying. Various types of structural equipments are being used to make the crepe in to different shapes. Primary milling and 
secondary milling is done prior to drying. For the purpose of drying, there are several techniques which are being used. In many industries, mechanical drier is commonly used. In this process DRC level archived about $60-62 \%$.

\section{METHODOLOGY}

A preliminary survey was conducted in the Rubber Park area of Bodhjungnagar Industrial Growth Centre to identify the potential sources of pollutants from the rubber based industries. During the field visit, an inventory was conducted for identification of major polluted stretch. The waste water samples were collected from the outlets of effluent treatment plants and also from the effluent disposal sites. The objective of the study is aimed to quantify the trend of deterioration of water quality within the study area. Analysis of water samples have been done in the environmental laboratory of the Tripura State Pollution Control Board using the standard method for testing of Water and Waste Water as adopted by APHA. Quantum of pollutants concentration and their characteristics have been assessed by the method of laboratory testing. This study analysed water quality data over three seasons with a view to understanding recent trends of deterioration on the surface water resources.

\section{PROBABLE IMPACTS ON ENVIRONMENT}

In order to identify the potential environmental risk, a survey was conducted in the Bodhjungnagar Industrial Growth Centre area. During the survey, it has been observed that huge quantities of ground water are being lifted from the underground and used in the factory for processing, which may lead to depletion of precious ground water resources. The volume of water being used is in turned generated as effluent during the processing. The individual waste stream from various sections has distinct effluent characteristics. The flow type and concentration of pollutants vary widely depending upon process, water use and cleaning system. The variation in waste flow and in its characteristics in respect of different processes depends on waste profile of the industry. As the acids are being used as additive for processing, hence the effluent generated from such type of industry is acetic in nature. To extend of acid usage is attributed to $\mathrm{pH}$ variation in the effluent. The effluents from rubber industries are being discharge into the nearby valley without taking any adequate care and treatment, it contained with high biological load. Such a common practice of disposal of effluent from the industries resulted offensive odours in and around the rubber park area. Lack of adequate treatment is responsible for such offensive odours, which in turn consequences to the human health and environment. Moreover, the physical and chemical elements present in the effluent are responsible for water pollution. Though, effects may be either short term or long term exposure. Hence, the effluent generated from the rubber industry is serious concern on environment.

\section{RESULT \& DISCUSSION}

Waste water samples are collected from five different locations of the rubber park area. The trend of deterioration of water quality of the project area is evaluated by laboratory testing. Seven water quality parameters are chosen in the study. The analysis report indicates that $\mathrm{pH}$ values of the various wastewater samples are found beyond the permissible ranges 6-9, which indicates that effluent generated from such type of industry is acidic in nature. The value of total dissolved solid (TDS) content is found within the range in many locations during summer and post monsoon periods. However, TDS values in two locations are found extremely worse condition during winter; the values are $3954 \mathrm{mg} / \mathrm{l}$ and $3030 \mathrm{mg} / \mathrm{l}$ respectively. Similarly, the values of Total Suspended Solid (TSS) are found beyond the permissible limit during winter. As per the CPCB standard, Sulphide content is permissible upto $2 \mathrm{mg} / \mathrm{l}$. However, from the analysis report, it has also been observed that the Sulphide content present in the waste water samples are ranges 3 to $25 \mathrm{mg} / \mathrm{l}$ in the entire waste water sample during post monsoon \& winter. On the other hand, the nitrogen content present in all the waste water samples are much more than the permissible limits during all the seasons viz. summer, post monsoon and winter. BOD loading of the sampling points have a maximum value of $725 \mathrm{mg} / \mathrm{l}$ in summer, $719 \mathrm{mg} / \mathrm{l}$ in post monsoon and $1080 \mathrm{mg} / \mathrm{l}$ in winter season.These apart, the oil and grease contents are also slightly declined from the standard limits of CPCB during all the consecutive seasons. It is obvious that the there is offensive odour problem in rubber park area of Bodhjungnagar Industrial Growth Centre. The ultimate finding of the of this study is that there is a water pollution of surface water resource due to massive disposal of effluent into inland water surface 
Evaluation of Physiochemical characteristics of disposed Rubber industry effluent: A Case

from the rubber based industries. The test results are given in the TABLE 1 and are illustrated graphically in Fig. 1 to 6.

Table: 1 SEASONAL VARIATION OF PHYSICOCHEMICAL CHARECTERISTICS OF RUBBER INDUSTRY EFFLUENT

\begin{tabular}{|l|l|l|l|l|l|l|l|l|}
\hline $\begin{array}{l}\text { Water } \\
\text { Samples }\end{array}$ & Season & $\mathrm{pH}$ & $\begin{array}{l}\text { TDS } \\
(\mathrm{mg} / \mathrm{l})\end{array}$ & $\begin{array}{l}\text { TSS } \\
(\mathrm{mg} / \\
\mathrm{l})\end{array}$ & $\begin{array}{l}\text { Sulphide } \\
(\mathrm{mg} / \mathrm{l})\end{array}$ & $\begin{array}{l}\text { Oil \& } \\
\text { grease } \\
(\mathrm{mg} / \mathrm{l})\end{array}$ & $\begin{array}{l}\text { Total } \\
\text { nitrogen } \\
(\mathrm{mg} / \mathrm{l})\end{array}$ & $\begin{array}{l}\text { BOD } \\
(\mathrm{mg} / \mathrm{l})\end{array}$ \\
\hline \multirow{4}{*}{ W1 } & Summer & $\mathbf{5 . 1}$ & 2066 & 101 & $\mathbf{2 0 . 0}$ & 5.1 & $\mathbf{1 9 6 . 1 0}$ & $\mathbf{7 2 5}$ \\
\cline { 2 - 9 } & Post monsoon & 8.5 & $\mathbf{3 0 3 0}$ & $\mathbf{3 6 4}$ & $\mathbf{2 3 . 4}$ & 15 & $\mathbf{1 4 0 . 0 7}$ & $\mathbf{7 1 9}$ \\
\cline { 2 - 9 } & Winter & 8.5 & $\mathbf{3 9 5 4}$ & $\mathbf{3 9 3}$ & $\mathbf{2 5 . 0}$ & 10 & $\mathbf{1 9 1}$ & $\mathbf{1 0 8 0}$ \\
\hline \multirow{5}{*}{ W2 } & Summer & 8.0 & 1631 & 32 & $\mathbf{2 1 . 2}$ & 4.2 & $\mathbf{1 9 6 . 1 0}$ & 84 \\
\cline { 2 - 9 } & Post monsoon & 8.0 & $\mathbf{2 9 4 5}$ & 31 & $\mathbf{2 5 . 6}$ & $\mathbf{1 1 . 7}$ & $\mathbf{1 1 2 . 0 6}$ & 89 \\
\cline { 2 - 9 } & Winter & 8.0 & $\mathbf{2 6 4 5}$ & 21 & $\mathbf{1 5 . 1}$ & 9.0 & $\mathbf{1 1 6 . 0}$ & 86 \\
\hline \multirow{5}{*}{ W3 } & Summer & $\mathbf{5 . 4}$ & 270 & 60 & $\mathbf{1 7 . 4}$ & 4.9 & $\mathbf{1 8 2 . 0 9}$ & 80 \\
\cline { 2 - 9 } & Post monsoon & 8.5 & 693 & $\mathbf{1 8 7}$ & $\mathbf{1 6 . 0}$ & $\mathbf{1 1 . 0}$ & 56.03 & 176 \\
\cline { 2 - 9 } & Winter & 8.0 & 1945 & $\mathbf{1 1 3}$ & $\mathbf{6 . 0}$ & 9 & $\mathbf{1 8 1 . 0}$ & 112 \\
\hline W4 & Summer & 7.5 & 240 & 21 & $\mathbf{3 . 6 0}$ & 3.3 & $\mathbf{1 9 6 . 1 0}$ & 14 \\
\cline { 2 - 9 } & Post monsoon & 7.5 & 125 & 23 & $\mathbf{1 9 . 4}$ & 4.4 & $\mathbf{1 2 6 . 0 6}$ & 16 \\
\cline { 2 - 8 } & Winter & 7.5 & 1137 & 78 & 2.00 & 5.0 & $\mathbf{1 9 3}$ & 56 \\
\hline \multirow{4}{*}{ W5 } & Summer & $\mathbf{4 . 9}$ & 232 & $\mathbf{3 9 6}$ & $\mathbf{1 4 . 4 0}$ & 4.1 & $\mathbf{1 9 6 . 1}$ & 6 \\
\cline { 2 - 8 } & Post monsoon & 7.9 & 154 & 86 & $\mathbf{1 6 . 2}$ & $\mathbf{1 0 . 6}$ & 70.04 & 18 \\
\cline { 2 - 8 } & Winter & $\mathbf{5 . 3}$ & $\mathbf{3 1 2 0}$ & $\mathbf{3 5 2}$ & $\mathbf{1 6 . 0}$ & $\mathbf{1 2 . 0}$ & $\mathbf{2 0 8}$ & 136 \\
\hline
\end{tabular}

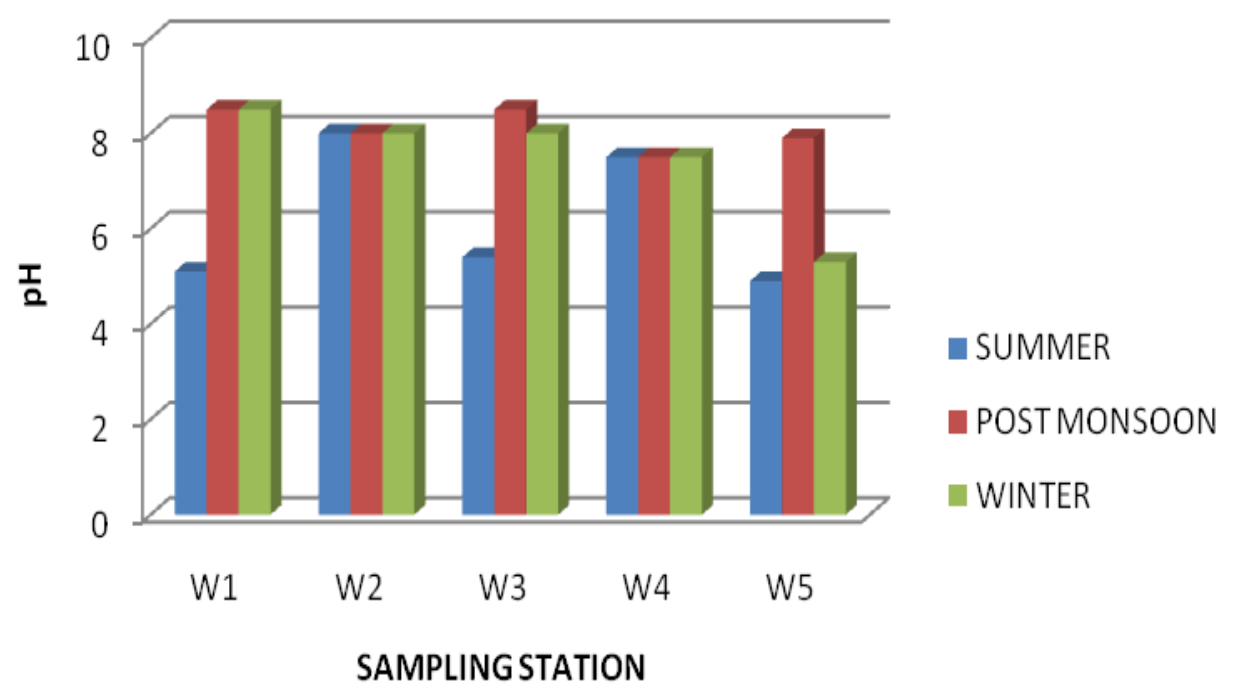

Fig 1. Variation of $\mathrm{pH}$ 


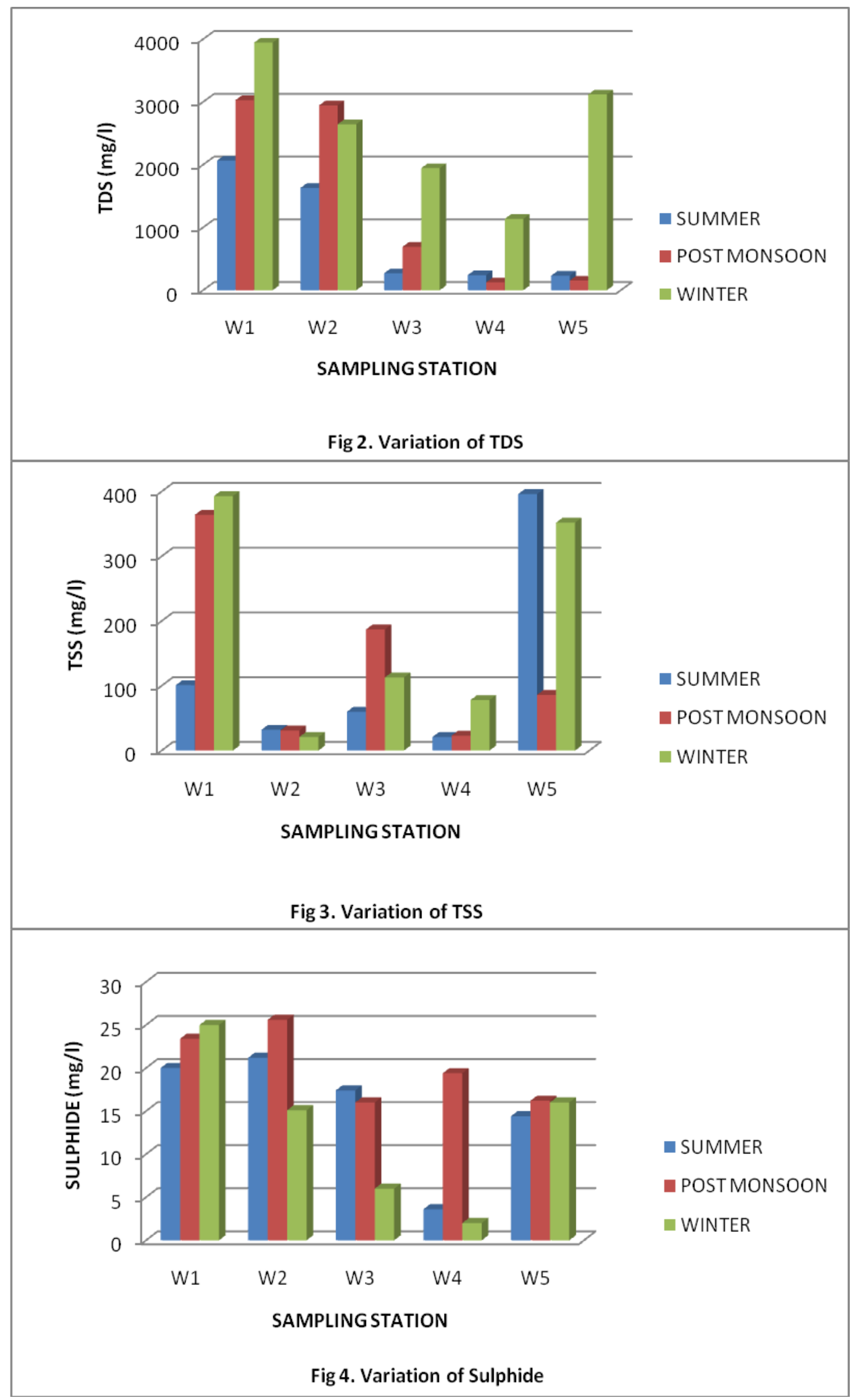




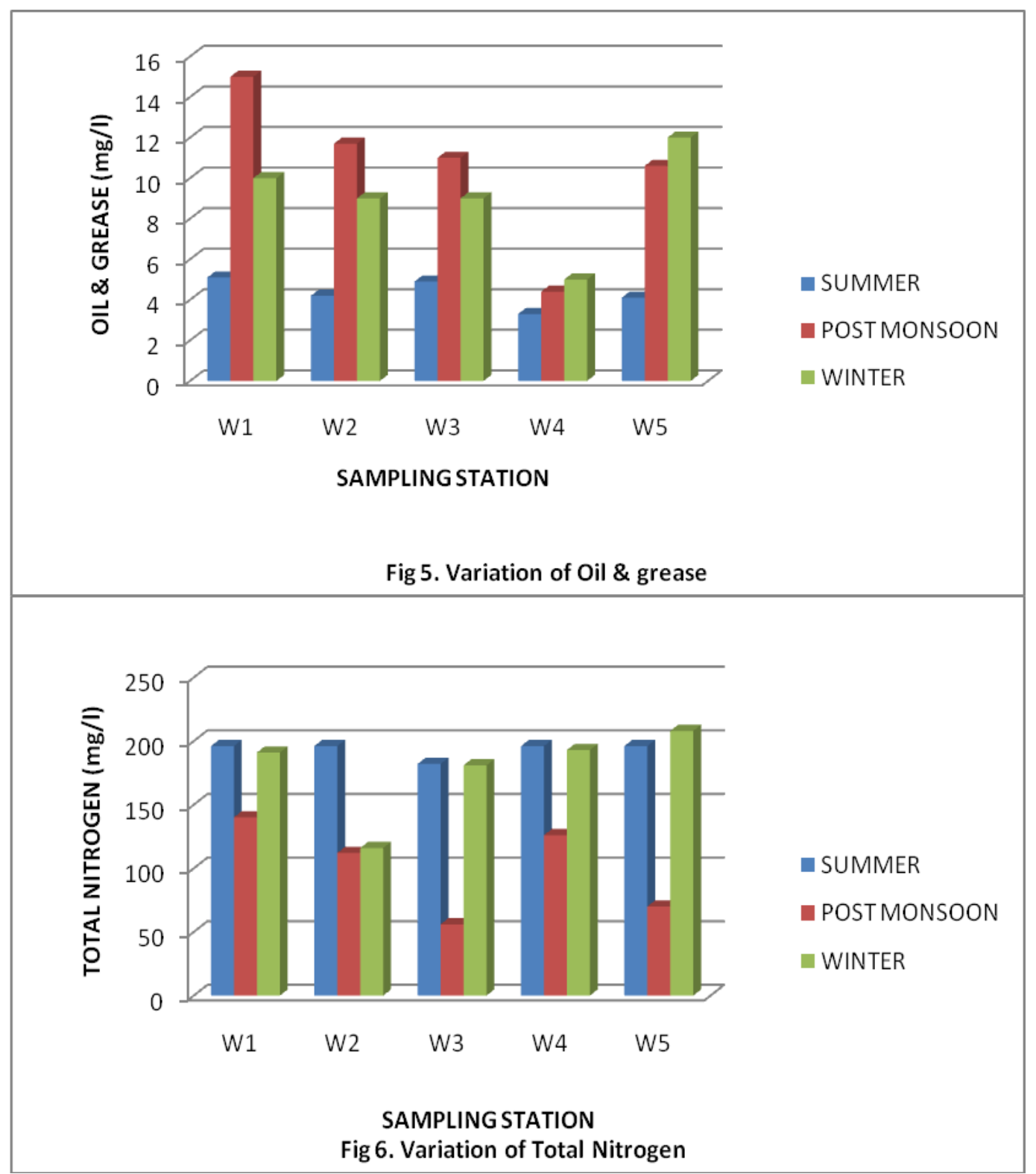




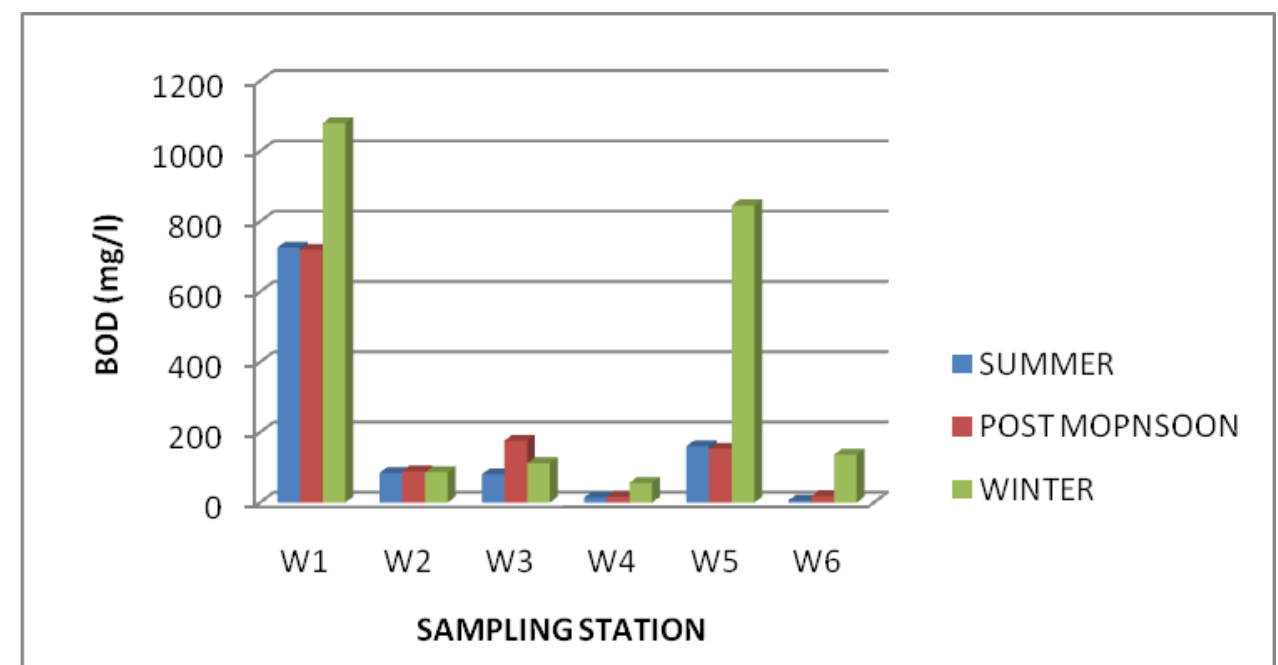

Fig.7. Variation of BOD

\section{CONCLUSION}

The study will help to give an idea about trend of deterioration of the water quality of Rubber Park of Bodhjungnagar Industrial Growth Centre. This study analysed effluent quality data over three seasons. Thus, this data can also be used to compare with the baseline data to assess the actual water pollution load. Moreover, these data can also be used to determine the gradual increase in pollution level with the increase in industrial activities in the area. However, the total water pollution load can only be assessed when the all other remaining physiochemical parameters will be evaluated. Ultimate finding of present study is immediate need to set up one common effluent treatment plant of adequate capacities and efficiencies for redressing the water pollution problems especially in the Rubber Park Area of Bodhjungnagar Industrial Growth Centre.

\section{ACKNOWLEDGEMENTS}

The authors of the paper would like to express their thanks and gratitude to the Prof. Mihir Deb, Hon'ble Chairman, Tripura State Pollution Control Board and Member Secretary, Tripura State Pollution Control Board for providing necessary information required for the completion of the present paper.

\section{REFERENCES}

[1] P.A.J. Yapa, "Effluent disposal and environmental pollution in rubber plantations in Sri Lanka", Proceedings of the international rubber conference "75 years of rubber in Sri Lanka, Colombo, September, 1984, 381-390.

[2] B. Goldar, S. Misra, and B. Mukherji, "Water pollution abatement cost function: methodological issues and an application to small-scale factories in an industrial estate in India", Environment and Development Economics, 6, 2001, 103-122.

[3] S. Samuel and S.M Muthukkaruppan, "Physico-Chemical Analysis of Sugar Mill Effluent, Contaminated Soil and its Effect on Seed Germination of Paddy (Oryza sativa L.)", International Journal of Pharmaceutical \& Biological Archives, 2(5), 2011, 1469-1472.

[4] B. Goldar and R. Pandey, "Water pricing and abatement of industrial water pollution: study of distilleries in India" Environmental Economics and Policy Studies, 4, 2001, 95-113.

[5] S. Dasgupta, M. Huq, D. Wheeler and C. Zhang, "Water pollution abatement by Chinese industry: Cost estimates and policy implications" Applied Economics, 33(4), 1996, 547-557.

[6] S. Pargal and D. Wheeler, "Informal regulation of industrial pollution in developing countries: Evidence from Indonesia”, Journal of Political Economy, 104(6), 1996.

[7] S. Chakraborty and S. Chakraborti, "An Analysis of the Baseline Environmental Status of Bodhjungnagar Industrial Complex - A Case Study", Journal of Chemical Biological and Physical Science, 4(3), 2014, 27092716. 